\title{
1. An introduction: mapping the field(s) of sustainable innovation
}

Frank Boons and Andrew McMeekin

\section{INTRODUCTION}

This handbook seeks to take stock of, and provide further impetus to, developing academic knowledge on how technological change affects levels of ecological and social impact of human activities. The role of technology in shaping the environmental impact of societies is captured in the IPAT formula that was coined in the early 1970s (Chertow, 2000; York, Rosa and Dietz, 2003), where impact (I) results from the combination of population levels (P), levels of affluence (A), and technology ( $\mathrm{T}$; this comprises artefacts - machines and material objects - as well as the social practices associated with the production and use of those artefacts). Consequently, understanding the rise of such impact, as well as designing and evaluating ways of reducing it, requires an understanding of processes of innovation and technological change. Furthermore, technological change and innovation can differentially affect the social position and opportunities of human beings, both individually and in various formations (families, communities, urban areas, countries). This indicates the relevance of an integrated perspective to: (1) facilitate the understanding of various ways in which evolving technologies shape social and ecological impact; and (2) help the design and evaluation of attempts to reduce negative impacts and maximize positive impacts.

Academic work in this area is widespread, and covers a range of disciplines from economics to engineering to sociology. Also, it is the key area of interest for interdisciplinary fields such as ecological economics and industrial ecology. Furthermore, it is addressed by multi-sectoral communities such as the Greening of Industry Network (GIN), Sustainable Transitions Research Network (STRN) and Sustainable Consumption Research and Action Initiative (SCORAI), where academics interact with practitioners from business organizations, governments, non-governmental organizations (NGOs) and civic organizations. This diversity is reflected in the range of labels that have been and still are in use for social processes associated with the environmental and social impact of technological change: alongside sustainable innovation, the topic is addressed as eco-innovation, environmental innovation, responsible innovation, and the greening of technological change, to provide a non-exhaustive list.

Consequently, the body of work covered in this handbook is not a readily recognizable entity. In fact, as the diversity and to some extent fragmented nature of academic inquiry can be seen as a distinctive feature, we aim to map the field in a way that adequately acknowledges this.

To provide a basis for our mapping, in Section 2 we outline our view on academic knowledge production, which is based in evolutionary epistemology. This leads us to expect disciplines to generate distinct conceptual lineages. The lineages that emerge from 
the disciplines of economics, sociology, as well as the interdisciplinary communities of innovation studies, management studies and environmental science, are presented in Section 3. Section 4 describes several of what we consider to be the most significant triggering moments originating from pre-existing epistemic fields in establishing the antecedent knowledge base for contemporary research on sustainable innovation. Section 5 provides the bridge between this mapping of the field and the chapters of the handbook. The parts of the book, and the chapters they contain, are then introduced in Section 6 of this chapter.

\section{IS THERE A FIELD OF SUSTAINABLE INNOVATION?}

Building on work in evolutionary epistemology (Toulmin, 1974; Hull, 1988b) and a processual view on social fields (Abbott, 2016), we posit that an academic field is adequately characterized as the evolving combination of (1) a set of problematics; (2) a community of researchers; and (3) a set of ideas guiding inquiry. Problematics consist of gaps between concepts and the observed world (but they include questions of design and normative ambition that are quite relevant in the sustainable innovation - SI - context). Such gaps may emerge as a result of changes in the observed world, as well as from different normative assessments of that world.

Following Abbott, we acknowledge that these three elements constitute each other: problematics are inherently shaped by sets of ideas, and what ideas are part of an academic field in part is a matter of who joins the community of researchers dealing with a specific problematic. Importantly, the dynamic of co-constitution may lead to highly structured and coherent fields, but it is equally possible to produce a fragmented and dispersed field. In this chapter we aim to provide insight into the academic enquiry into SI from the starting assumption (to be validated) that, at least up till now, the inquiry into SI has the latter quality.

The dynamic of co-constitution is driven first of all by the way in which individual researchers seek recognition within their professional context by constituting distinct lineages of ideas. In this process, they need to find a balance between originality and building on legitimacy (Hull, 1988a). Second, over time, some problematics are 'solved' and then succeeded by others. To some extent, this is driven by societal demands, that is, non-academics seeking to achieve particular private or collective goals. This results in lineages of concepts/research questions that evolve in this complex environment, as well as in relation to each other. These lineages are the subject matter of this handbook, and this introductory chapter maps the field of SI by describing a number of key lineages.

\section{LINEAGES THAT TOGETHER FORM THE FIELD OF SI}

As indicated above, we aim to engage with the study of sustainable innovation by foregrounding from the outset that it does not constitute a well-defined or institutionalized epistemic field or community. As such, we aim to represent the topic as it has been developed through multiple conceptualizations, drawing on diverse disciplinary approaches. 
At times, lineages have run almost entirely parallel to each other; in other instances, there have been important interactions and synergies. The different streams reflect both different problematics of sustainable innovation (and its antecedent conceptualizations) and the dynamics of different epistemic communities seeking to institutionalize specific lines of research inquiry.

Our approach to capturing the field of sustainable innovation involves judgements about what to include and how to present prominent research lines. This necessarily requires interpretive steps, on which we report in this section. Our approach iteratively combined the following sources:

1. Reviews of (the history of) parts of the field as published in key journals and relevant research handbooks, and introductions to special issues. Each of these sources explicitly or implicitly aimed to configure future research lineages by channelling previous research towards specific audiences (for example, Berkhout, 2011 for the management studies audience), policing the boundaries of certain fields or lineages (Røpke, 2004, 2005 for ecological economics) or promoting a specific conceptual framework (Smith, Voss and Grin, 2010 for the multi-level perspective) to configure future research. In contrast, our approach for this handbook is to acknowledge the 'umbrella concept' characteristics of sustainable innovation research, to understand the fragmentation of research lines and to give some prominence to latent, partial or tentatively emerging crossovers.

2. Our own knowledge of sustainable innovation research and expert opinions as expressed during a workshop in May 2017.

3. Bibliometric analysis around key concepts relating to sustainable innovation (that is, citation analysis, main path analysis, and text mining of abstracts). We used these as background information, and eventually decided not to build this introduction around a bibliometric analysis. The reason is that the analysis in our view can only show parts of the evolving field, and thus provides a biased view that does not help readers to become accustomed to its characteristics. In other words, in our view, a handbook should provide the expert knowledge that a bibliometric analysis cannot provide.

4. On the basis of these sources, we have gone back to some important conceptual articles, which were not explicitly reviewing specific research lines, but nevertheless did provide syntheses of a wide range of literature and aimed to provide conceptual frameworks to configure further research agendas. For example, Kemp and Soete (1992) pulled together a wide range of scholarship in 'The greening of technological progress', published in Futures as a call to arms for the innovation studies community, and Rennings (2000) sought to define 'eco-innovation' in 'Redefining innovation eco-innovation research and the contribution from ecological economics', published in Ecological Economics.

Out of this approach we construct a narrative in which we start with academics and their reaction to the academic and practical challenge of environmental impact of human societies; they do this sometimes within the boundary of a discipline, but also in a way that constitutes new interdisciplinary fields (Section 4). This activity then leads to the emergence of specific conceptual lineages, which are concisely described in Section 5. 
We stress that the narrative is there to enable presentation of the material; in reality, disciplines and lineages constitute each other.

\section{DISCIPLINES, FIELDS AND THEIR RESPONSES TO ENVIRONMENTAL PROBLEMS}

This section aims to describe several of what we consider to be the most significant triggering moments originating from pre-existing epistemic fields in establishing the antecedent knowledge base for contemporary research on sustainable innovation. This endeavour is not without its challenges because the epistemic fields of 30-40 years ago bear varying resemblance to their contemporary manifestations. A good example of this, and the first that we will consider, is the field oriented towards understanding the social and economic dynamics of science, technology and innovation. As recognized in a recent special issue of Research Policy (2012), a meta-field, now sometimes identified in Europe as 'science, technology and innovation studies' (STIS), may best be characterized as constituted by the relatively autonomous, but interacting subfields of 'innovation studies' (mainly economics, where several decades ago, academics were likely to self-identify as economists of technological change), entrepreneurship studies and science and technology studies (STS, sociology oriented) (Fagerberg, Fosaas and Sapprasert, 2012). The first and third of these feature prominently in this handbook, with their respective knowledge bases triggering both distinctive and synergistic research lines.

The second emergent field we consider arose as a disciplinary response to environmental challenges from the mainstream sociology discipline (which was quite distinct from the work within STS). While the emergence of environmental sociology as a subdiscipline can be traced at a general level, we focus on the emergence of a narrower, but for our purposes, more relevant academic discourse around ecological modernization theory (EMT).

The third concerns the creation of new interdisciplinary epistemic communities, where critical ecologists joined forces with economists and engineers, leading to the institutionalization of ecological economics and industrial ecology respectively, each now with their own professional associations, conferences and dedicated journals. With the persistent involvement of ecologists and scholars and practitioners with expertise in actual material and energy flows, these communities are distinctive in their consistent attention to economy/industry-ecology relationships.

Fourth, we consider how the mainstream management studies discipline applied and adapted its core theories to understand the prospects for sustainability-oriented innovation. Here a distinct focus emerged as scholars responded to the problematique of the environmental and social impact of business organizations, and increasingly systematic efforts of firms to address those impacts and incorporate these into their operational and strategic routines, rather than see them as externalities.

\section{The Economics of Technological Change and 'Innovation Studies' Meet the Limits to Growth Thesis}

Accounts of how innovation scholars initially engaged with environmental problems paint a similar picture (Kemp and Soete, 1992; Foray and Grübler, 1996; Smith et al., 
2010), although at the time, the scholars involved were more likely to self-identify as economists of technological change. Some early statements by Rosenberg, Simon and Ruttan on the technology-environment relationship went 'largely unnoticed' (Foray and Grübler, 1996) until a highly prominent debate between the Club of Rome modellers behind Limits to Growth (Meadows et al., 1972) and innovation scholars at the Science Policy Research Unit (SPRU) at the University of Sussex, UK (Cole et al., 1973; for the debate see Luten, 1980). There were three significant features to this debate that help in understanding how future research on sustainable innovation would progress. First, the SPRU critique was highly sympathetic to the concerns raised in the Limits to Growth report, agreeing that economy-ecology-technology interactions required increased academic and policy attention in the face of urgent (even then!) challenges. Second, however, and at the heart of their critique, the SPRU scholars questioned the assumed fixity of biophysical limits to growth - the Club of Rome's 'Malthus in, Malthus out' approach was likely to underestimate the potential for technological innovation and changes in economic development paradigm to stretch those limits. As such, biophysical limits were seen as real, but also subject to social, political, institutional and economic construction. Third, this led Freeman (for example, 1984, 1992) in particular to argue for attention to long waves of techno-economic development. In his view, the emerging information and communication technologies (ICT) technoeconomic paradigm and hopes for a future 'green' techno-economic paradigm could stretch biophysical limits with continued economic development, via dematerialization and (partial) decoupling of economic growth and environmental degradation. In this sense, early innovation scholarship arguably foregrounded the broadest and most long term of perspectives.

Freeman's intervention was and is characteristic of much of the research undertaken by innovation scholars: applying, and then adapting, the prominent theories and approaches in the wider field of innovation studies to the special case of environmental problems and long-term trajectories towards sustainable development. Prominent examples, which exemplify this tendency and triggered further work now recognized as constituent of contemporary sustainable innovation research include the following:

- Typologies and characteristics of different types of environmental technology (Kemp and Soete, 1992). This work prefigured durable debates about appropriate definitions of eco- or sustainable innovation.

- The 'double externality' or double market failure problem of environmental technologies (Kemp and Soete, 1992; Jaffe, Newell and Stavins, 2003), which has remained a feature in debates about environmental innovation policy.

- Application of the systemic model of innovation to long-term environmental problems and implications for environmental technology policy (Soete and Arundel, 1993; Freeman, 1996). The durable concept of innovation systems from the core of innovation studies has continued to be an influential contributor to the sustainable innovation field, especially through the technological innovation system (TIS) approach.

- The determinants of environmental technology generation and adoption (Ashford, Ayres and Stone, 1985; Green, McMeekin and Irwin, 1994). This earlier work, which initially concerned the relative significance of markets vs regulations in 
stimulating environmental innovation endured and expanded to evaluate a wider range of determinants and settings for a broader range of eco-innovations.

- The need for radical transitions of technological regimes (Kemp and Soete, 1992; Kemp, 1994) initially deployed notions of technology regimes from evolutionary economics, but subsequently incorporated ideas from STS, leading to elaborated frameworks such as the multi-level perspective (see below).

- Firm and industrial environmental innovation strategies (Fischer and Schot, 1993), which initially investigated detailed firm-level case studies (for example, Irwin and Hooper, 1992) and developed simple models for the management of environmental R\&D and innovation (Winn and Roome, 1993; Roome, 1994). While its focus is broader than corporate innovation, the journal Business Strategy and the Environment has continued to provide a forum for these debates, increasingly in combination with ideas from the wider community of management and organization scholars (see below).

\section{STS Confronts the Controversies of Environmental Problems and 'Risky' Technologies}

Sociologists of science and technology initially approached the emergence of environmental problems with different questions to those addressed by the (economics of) innovation studies community, with social constructivist framings playing a highly prominent role. Yearley (2008) recalls early scholarship in this area as oriented towards a general theme of 'knowing nature', with a significant focus on climate change and the contested technology of genetically modified (GM) crops. Key issues included the social construction and use of knowledge and expertise in policy-making, the dynamics of environmental controversies, and public participation in environmental understanding and decision-making (Irwin, 1995).

Originating in earlier work on controversies as a site for technology assessment (Rip, 1986), STS scholars mobilized social constructivist thinking to develop new approaches and tools for technology decision-making. The late 1980s were particularly significant for the development of constructivist approaches in STS, with the seminal contributions marking a shift in focus from science to technology. The theoretical developments described in Bijker, Hughes and Pinch (1987) established important correctives to pre-existing ideas grounded in an internalist logic for technology development (including strong and weak variants of technological determinism). The social construction of technology (SCOT) approach introduced concepts of interpretative flexibility and the multiple actor-groups involved in shaping the forms and uses of technologies. Interestingly, the Bijker et al. (1987) volume had no contributions explicitly considering environmental challenges, although Callon's chapter, 'Society in the making: the study of technology as a tool for sociological analysis', discusses the (failed) attempt to introduce electric vehicles in France.

However, the new turn to technology for STS did spark the development of new formulations for technology assessment and technology decision-making. The approach of constructive technology assessment (CTA) (Rip and Van den Belt, 1988; Rip, Schot and Misa, 1995) was a prominent variant of this, also applied to environmental problems and clean technology development (Schot, 1992). Strongly grounded in constructivist commitments, CTA takes the view that technology decision-making should be informed 
by multiple stakeholder groups and aim at preserving plurality rather than precipitous closing down of options, to avoid undesirable irreversibilities becoming established. This early work on CTA has endured in its own right, but also triggered the development of alternative concepts, including recent manifestations in debates about responsible research and innovation.

\section{Cross-fertilization Between the Economics of Innovation and STS - Towards Quasi- evolutionary Thinking}

With the broader development of a new sociology of technology in the 1980s, some scholars started to explore crossovers with theoretical perspectives from the economics of technological change and innovation, especially with concepts deriving from evolutionary approaches (for example, Van den Belt and Rip, 1987). This research, which emerged under the banner of a quasi-evolutionary model of technological change (Rip, 1992, 1995), was consequential in several ways: (1) in arguing for attention to the socially constructed nexus between evolutionary variation and selection mechanisms; (2) in broadening the notion of technical regime to socio-technical regime, expanding the range of actors and their various interpretations of problems and potential solutions; and (3) bringing sociological insight to the formation and development of radical niche innovations, in particular examining how niches could be protected from wider and mostly hostile selection processes.

Much of the work in this vein during the early 1990s was brought together in Rip and Kemp's (1998) synthesis chapter. Ideas sketched in this chapter on 'technology and the environment' set the scene for future work elaborating the analytical and normative projects of the multi-level perspective (MLP) and strategic niche management (SNM).

\section{Configuring a New Subfield of Environmental Sociology and the Development of Ecological Modernization Theory}

For our purpose, the most significant development from the new environmental sociology (see, for example, Dunlap, 2002 for a personal review of the field) centres on ecological modernization theory (EMT). Similar to the initial research by innovation scholars, EMT directly foregrounded the economy-environment relationship, also proposing the thesis that continued modernization would provide solutions through decoupling the relationship. Their thesis drew on broader notions of reflexive modernization, a cultural shift whereby societies would increasingly recognize environmental problems and adapt behaviours (in production and consumption) accordingly. Market-incentivized technological change would feature heavily in this process - for example, through transforming the chemical industry: '[ $\mathrm{t}$ ]he dirty and ugly industrial caterpillar transforms into an ecological butterfly' (Huber, 1985, p. 20, translated in Spaargaren and Mol, 1992, p. 334). It is interesting and notable for our current purposes that Kemp and Soete (1992) mention similarities between EMT and the notion of a future green techno-economic paradigm, although there was little further interaction to explore theoretical crossovers.

EMT proved to be both influential and controversial in policy and academic debate. As a significant discourse in environmental policy (Hajer, 1995), it acted as an umbrella for environmental policy in several countries, which adopted a focus on environmental 
technology policy under market conditions during the 1990s (for example, Bulkeley, 2001 for Australia; Gouldson and Murphy, 1997 for the UK; Hajer, 1995 for the Netherlands). Critics argued that this led to over-optimism in technology fixes within existing institutional arrangements and especially a focus on quick win-win eco-efficiency improvements, which deflected attention from the deeper changes required to meet long-term environmental problems (York and Rosa, 2003).

Within the new environmental sociology, EMT engaged in a prominent and sometimes hostile debate with neo-Marxist scholars centred around the 'treadmill of production' idea (Schnaiberg, 1980; Schnaiberg and Gould, 1994). This appears to have some similarity to the clash between SPRU and the Limits to Growth authors over biophysical limits and the prospects of decoupling economic growth from environmental degradation.

EMT scholarship subsequently evolved through several generations, with contributions about state-market relations (and associated implications for environmental technology governance) and also through a refocusing towards issues of sustainable consumption practices (especially Spaargaren, 2000). In general, EMT scholarship has progressed independently from other work on sustainable innovation; however, the shift towards integrating research on sustainable consumption has emerged strongly over the recent period, initially in terms of wider policy and academic debates about 'sustainable consumption and production'.

\section{Configuring the New Subfields of Ecological Economics and Industrial Ecology}

Again, in somewhat parallel and unconnected ways, a number of contributions from heterodox economists, management and engineering scholars, ecologists, and scholars from beyond conventional academic disciplines provided blueprints for what future economies would need to look like in order to become environmentally sustainable. Authors such as Kenneth Boulding (1966), Ayres and Kneese $(1969,1971)$ and Georgescu-Roegen (1971) developed 'preanalytic visions' (Røpke, 2004), inspired by the then emerging interdisciplinary paradigm of systems science. Each of them combined insights from physics, biology and economics to analyse the way in which physical and economic processes interacted. This led to considerations of the physical limits to economic growth, as well as the inevitability of waste. This early work started out as flagging an omission in the work of most economists, who took for granted the availability of resources from nature, and natural ecologies acting as sinks for wastes resulting from economic processes.

In addition to combining economics with insights from physical sciences into a more systemic perspective, these early contributions provided visions of what an ecologically sustainable economy would look like; they were less pronounced on developing an understanding the social processes that would be required to move societies towards those sustainable futures. Each of these visions includes distinct descriptions of yet to be created systems of production and (sometimes) consumption; thus, they at least imply technological change and innovation, as well as associated social and organizational innovation.

These early ideas proved highly significant in mobilizing the institutionalization of two new interdisciplinary fields within the larger area of the environmental sciences: ecological economics (EE) and industrial ecology (IE). Both are significant for understanding research on sustainable innovation, which has featured as one important aspect of their respective lines of scholarship. Also, in both cases, more self-consciously identified 
innovation scholars have made important contributions to their debates and, vice versa, scholarship from IE and EE has contributed to developments within the innovation studies community (as recognized in both the Berkhout, 2014 and Smith et al., 2010 pieces). One feature marks out these two new subfields from the early efforts from innovation studies and environmental sociology. They both adopted a much more direct interrogation of economy-environment interactions by studying and theorizing about actual material and energy flows in the economy.

Røpke (2004, 2005) describes the emergence and institutionalization of ecological economics as a new field via a mobilization of scholars from across a variety of disciplines. A key moment in the institutionalization of the field was the establishment of the journal Ecological Economics. Costanza (1989, p.1) in his editorial introduction to the first issue set out the ambition to move beyond the existing disciplines: 'Environmental and resource economics, as it is currently practiced, covers only the application of neoclassical economics to environmental and resource problems. Ecology, as it is currently practiced, sometimes deals with human impacts on ecosystems, but the more common tendency is to stick to "natural" systems'. Røpke (2005) argues that it is hard to define the core research lines of the field, given its explicit emphasis on plurality, but it is clear that the subdiscipline has been an active contributor to debates on environmental and sustainable innovation.

The creation of industrial ecology as a new subfield, in some ways, shared a common intellectual heritage to ecological economics. Indeed, as Røpke remarks, 'there are important overlaps between ecological economics and industrial ecology, as both fields cover studies on social metabolism - material and energy flows in the economy - but the composition of followers differs, as engineering and management are more prominent in industrial ecology' (2005, p. 273). This prominence of engineering and management meant that industrial ecologists paid more attention to very detailed empirical analyses of industrial processes, with an emphasis on describing material and energy flows and concrete proposals for how linear industrial processes could be transformed into closed loops through the reuse of waste streams and more efficient processes to transform inputs. The relative balance of engineering and management approaches is also evident in early work. Ayres and Ayres (1996) provided very detailed analyses of material flows in a range of industrial sectors; Socolow et al. (1994) paid more attention to business processes, management approaches and policy-making, including contributions from innovation scholars.

\section{Management and Organization Scholars Engaging with the Natural Environment and Social Responsibility}

Scholars in the field of management and organization studies have a long tradition of addressing questions of responsibility towards societal problems. Early work is in some ways exemplified by the controversy over Milton Friedman's dictum that 'the social responsibility of business is to increase its profits' (Friedman, 1970). This thesis, and the debate it raised, reflects an orientation that positions business and government in separate corners, and with environmental and social impacts the concern of the latter. In this debate, technological change and innovation do not play a major role.

As a result of a changed appreciation of the types and scope of technological change required for sustainable development, combined with increased insight into alternative 
forms of government-business interactions, the question of how business firms could relate to environmental issues changed dramatically in the 1990s. A community of researchers emerged in the form of the Greening of Industry Network, which had an academic as well as societal ambition, and which spawned a dedicated journal, Business Strategy and the Environment. Also, Porter and Van der Linde (1995) initiated a new line of research with their thesis about the relationship between regulation, environmental innovation, and competitiveness.

In the slightly separate community of the Academy of Management, scholars started to use existing theories, most notably the resource-based view and institutional theory, to address the ways in which firms were engaging with ecological problems. A 1995 special issue of the Academy of Management Review contained a number of influential articles that sought to map the relevance of sustainable development for the study of business organizations. One contribution was Stuart Hart's (1995) 'Natural-resource-based view of the firm', which explicitly extended existing theory to include strategizing in relation to environmental and social impacts. This work explicitly theorized about 'proactive' strategies of pollution prevention, and product stewardship, thus relating more directly to technological change. Another influential theoretical strand was organizational institutionalism, which seeks to understand how organizational characteristics result from the striving of managers to secure legitimacy. Such theorizing fits well with dynamics where the legitimacy of products and/or organizational activities is contested, and consequently contestation around issues of sustainability became a major area of application (Hoffman and Ventresca, 2002).

From this initial work a much more diverse body of work has emerged (Bansal and Hoffman, 2012), now with a dedicated journal, Organization \& the Natural Environment. Although in many cases it relates directly to innovation, it is less explicit in its consideration of how organizational changes actually affect the physical attributes and impacts of products and production processes (Boons, 2013).

\section{FROM EPISTEMIC FIELD RESPONSES TO THE PROPAGATION OF DURABLE RESEARCH LINES}

The foregoing discussion helps our understanding of sustainable innovation scholarship in several ways: (1) in understanding how existing disciplines started to grapple with increasing awareness and societal attention to environmental problems; (2) the formation of new subdisciplines and associated epistemic communities; (3) common and divergent themes in the study of sustainable innovation; (4) the venues and outlets for conference papers and significant publications - and how certain journals end up hosting specific debates; and (5) crossovers, 'incursions' and boundary policing across debates and epistemic communities. We now turn to several more specific research lines that constitute the study of sustainable innovation. In doing so, we switch from the field-triggering perspective above to a focus of research topics and lineages. We do so, because to a greater or lesser extent in each case, the research lines that they represent have benefited from contributions beyond the boundaries of the epistemic communities discussed above. Given the normative orientation of much sustainable innovation scholarship within these research lines, each of them is associated with distinctive debates and approaches to ques- 
tions of governance, policy and purposeful guiding of innovation trajectories towards more sustainable futures.

\section{From Types of Environmental Technology to Defining Eco-innovation}

The first research lineage, common to all the epistemic fields outlined above, continued to debate and provide definitions for different types of innovation response to sustainability problems. Some of this rehearsed existing typologies from innovation studies, which distinguished product and process, and/or incremental and radical innovations. Much of the early work debated the relative merits of end-of-pipe process technologies, which dominated industrial responses, against what became termed clean technologies, which aimed to integrate technological changes within production processes - many of these studies were published in engineering journals (for example, Clift, 1995; Vickers and Cordey-Hayes, 1999). Industrial economists paid close attention to very detailed and specific cases of industry-specific material and energy flows, examining how they could be reduced or conserved (closing the loop) (for example, Ayres and Ayres, 2002; and many papers in the Journal of Cleaner Production, Journal of Industrial Ecology and engineering journals).

Berkhout (2014) summarizes the management literature, showing three effects of environmental technology: (1) information effects: technologies and techniques for improving information about resource availability and environmental problems; (2) efficiency effects: eco-efficiency innovations to reduce environmental problems; (3) transformational effects: technologies that fundamentally change economic process towards the visions of closed loop, non-fossil fuel production.

While much of the initial attention focused on process technologies, studies of green products and eco-design also started to emerge. ${ }^{1}$ Interest also grew around the idea of product-service systems, especially in engineering-oriented journals such as Journal of Cleaner Production, Journal of Manufacturing Technology Management and International Journal of Advanced Manufacturing Technology (see Tukker, 2015 for a review). These picked up on and sought to operationalize and refine the early visions of scholars, including Stahel (1982).

Much of this earlier and ongoing work was consolidated into a proposal for a broader conceptualization that included but went beyond environmental technologies. Rennings (2000) provided an early statement for a definition of eco-innovation, which subsequently became a focal point for further empirical and theoretical work. Eco-innovation was defined as having a clear and tangible positive ecological impact (whether intended or not) and could be technological, organizational, social or institutional.

Subsequently, there have been ongoing debates and attempts to clearly define ecoinnovation. The success of this is disputed. Berkhout (2011), for example, claimed that definitional disputes were largely resolved. But, Angelo, Jabbour and Galina (2012) found in a meta-review that other review papers were split in their use of 'environmental innovation' (65 per cent), eco-innovation ( 22 per cent) and green innovation (only 13 per cent). Hojnik and Ruzzier (2016) claim that empirical studies continue to exhibit significant differences in their definitions of innovations studied.

Nevertheless, studies of eco-innovation have matured significantly - beyond the definitional issues, the most significant strand of research has been concerned with the determinants of environmentally oriented innovation, of whatever definition. 


\section{Determinants of Eco-innovation}

A major research line for the study of eco-innovation (and its antecedent conceptualizations) has been concerned with the role of public policies and market incentives in stimulating their development and adoption. The 'Porter hypothesis' that strict environmental regulations could generate competitive advantages for firms remains one key 'touchstone' for debates about the determinants of innovations.

Kemp and Pontoglio (2011) identified four different research streams, which also reflect different disciplinary contributions: (1) theoretical models of incentives; (2) economic studies of policy instruments; (3) cases studies; and (4) surveys of firms. This research line has been strongly influenced by the definitional disputes discussed above, leading Kemp and Oltra (2011) to suggest that distinctions concerning what counts as an innovation are insufficiently used.

Nevertheless, work on the determinants of eco-innovation has matured. It became an important focus of the Organisation for Economic Co-operation and Development (OECD) and European Commission (EC), and some national governments (for example, Germany). This provided funding for a new survey and led to eco-innovation being included in the European Community Innovation Survey (CIS). Evidence pointing to the relative importance of different policies for stimulating eco-innovation remains mixed and disputed, but the availability of larger datasets has allowed for much finer-grained understanding to be generated, revealing important sectoral differences (Berkhout, 2011).

\section{Consolidating the Systemic Innovation Perspective}

The shift from environmental technology to eco-innovation represents one aspect of how sustainable innovation research has broadened its unit of analysis. A second conceptual broadening involved further conceptualizing and analysing the systemic aspects of innovation in two complimentary ways, building on ideas discussed earlier that emanated from the wider innovation studies field and crossovers between evolutionary and STS approaches. The first involves treating a socio-technical system as the entity that changes, leading to analysis of system innovation; the second further develops the idea that multidimensional innovation systems - comprising actors, institutions and technologies - are responsible for the development and use of new technological innovations.

In the first strand, Kemp (1994) initially drew on evolutionary economic approaches to innovation, which had proposed the notion of technological regime - the shared cultural-cognitive understanding of engineers and entrepreneurs - which accounted for the direction and speed of technological change. Over the course of the next several years, these initial ideas were developed in several ways. First, research on strategic niche management was further developed as a mechanism for overthrowing existing regimes with new and radical technologies - for example, the electric vehicle. This extended its conceptualization of niches from evolutionary economics, by drawing on ideas from STS to emphasize social network formation, cultural articulation processes, and so on, to understand how niches could be protected from harsh selection processes to develop internal momentum and ultimately challenge incumbent systems. The ideas of SNM sparked a major and continuing research line at the interface of policy and academic analysis (Schot and Geels, 2008). 
Second and related, Rip and Kemp (1998) and Geels (2002) proposed and elaborated a multi-level perspective (MLP) for understanding how major socio-technical system innovation occurred over decades through interactions (and struggles) between radical niches and incumbent regimes under fluctuating pressures from an exogenous and slowchanging landscape. The MLP later drew on ideas from institutional theory to further develop its conceptualization of how regimes are institutionalized (Geels, 2004).

The 'allure of the multi-level perspective' (Smith et al., 2010) lay in the plurality and interdisciplinarity of its framework. As a relatively open framework, MLP-inspired research has further developed to take account of the politics of transition, geographical differences, cities as sites for sustainable transitions and grassroots innovation, which could be seen as proto-niches, or transitions in the making. As such, the MLP has been especially successful in providing a platform for innovation scholars to engage in debates with other disciplines. A distinctive feature of this research line is its focus on socio-technical change processes, which are assumed to be of the depth, scope and scale demanded by modern environmental problems. However, most work in this area applies social scientific approaches to questions of sustainable system transition, rather than engaging directly with the relationship between socio-technical and ecological systems.

The second strand of research developed from the innovation systems concept, especially early work on technological systems (Carlsson and Stankiewicz, 1991) to study the emergence and use of technologies that contribute to solving environmental problems. In particular, the idea of technological innovation systems (TISs) was developed to identify and analyse critical system functions required for stimulating technology development, with a lot of attention to renewable energy technologies (Jacobsson and Bergek, 2004; Hekkert et al., 2007). Although precise definitions of system functions differ, in general they point to the importance of entrepreneurial activities and experimentation; knowledge development and diffusion; providing orientation to search processes; creating markets; mobilizing resources; and securing policy legitimacy (Hekkert et al., 2007; Bergek et al., 2008). Most early scholarship analysed the relative contribution of different functions to the effective working of the system as a whole, partially with respect to its performance in terms of the generation and use of new technologies. The TIS/functions approach has been applied extensively in empirical analyses of emerging technologies across a wide range of national contexts.

\section{From Pluralizing Technology and Innovation Decision-making to Responsible Research and Innovation}

Early STS-inspired work continued to develop a distinct lineage based on constructivist approaches to science, technology and innovation decision-making. With a strong normative orientation, scholars addressed key issues of decision-making process, proposing alternatives to conventional decision-making, which was viewed as narrowly designed by privileging (scientific) expertise, the participation of a narrow group of decisionmakers, with the aim to close down options on the basis of (often) ex post cost-benefit analysis, often in favour of incumbent interests. Against this, STS-inspired alternatives promoted an 'opening up' (Stirling, 2008) of decision-making, with proposals for wider societal participation, anticipatory and real-time assessment and preserving diversity of options. From the vantage point of contemporary debates, much of this work has been 
consolidated and 'rebranded' under the banner of 'responsible research and innovation', which is highly promoted by European funding agencies. Within this new institutional context, new frameworks have been proposed, offering the requisite characteristics required to promote responsibility - for example, anticipation, reflexivity, inclusion and responsiveness (Stilgoe, Owen and Macnaghtnen, 2013).

\section{From Firm Environmental Management to Sustainable Strategy to Sustainable Business Model Innovation}

The work originating from the organization and management field arguably starts with work on environmental management and accounting (Roome, 1994; Ilinitch and Schaltegger, 1995). This work follows the societal problematique where environmental impacts of firms, previously the subject of governmental regulation and monitoring, increasingly become seen as part of their own responsibility. This societal dynamic in many Western societies spawns academic work that studies firms' attempts to monitor such impacts, and communicate their 'environmental performance' to their stakeholders. Combining such monitoring with financial accounting provides more transparency of the costs of waste streams, stimulating process innovations to prevent such waste streams. An alternative route is through the development of standards and environmental labels, which communicate the environmental performance of firms and their products to (corporate) consumers. This provides further impetus to product and process innovation (see Boons et al., 2000 for an analysis of this longitudinal dynamic in Dutch industry). Much of this work parallels the environmental innovation lineage, in terms of addressing questions of whether, and under what conditions, increased transparency leads to product and process innovations with reduced environmental impacts.

Hart's (1995) natural resource-based view links these trends to a recognized management theory that posits that firms derive competitive advantage from developing the organizational capabilities to develop environmental process and product innovations, and more generally engage in sustainable development. Most of this work, which marks a change from a focus on (operational) management to corporate strategizing, focuses on organizational capabilities and the way they contribute to competitive advantage; this work typically is much less explicit about the resulting reduction in environmental impact (Boons, 2013), as well as the precise artefacts that support these capabilities. The hypothesis formulated by, and derived from Hart's original statement, has been well studied in a variety of industrial and geographical contexts (Hart and Dowell, 2011).

The publication of Stubbs and Cocklin (2008) marks the emergence of a distinct construct - the sustainable business model - which has rapidly become dominant among scholars seeking to analyse evolving business practices in relation to sustainable innovation. Research on sustainable business model innovation builds on several pre-existing research lines: (1) scholarship from the late 1990s onwards in the general management and strategy literatures on business model innovation; (2) the literature from innovation studies relating to eco- and sustainable innovation; (3) the engineering and management literature related to industrial ecology and antecedent visions (Berkhout, 2011; Boons and Lüdeke-Freund, 2013). Boons and Lüdeke-Freund argue that the new topic coalesced around two main focal questions. First, how do business models combine ecological, social and economic value? In this sense the emerging research is still split between studies 
that focus mainly on ecological concerns and those that incorporate the social dimension as well. Second, how do business models provide a link between individual firm and wider production-consumption systems? Studies either present normative blueprints for sustainable business models (at different scales) or examine the development of actually emerging business models. A recent assessment of the burgeoning stream of literature on business models by Massa, Tucci and Afuah (2016) presents the work on sustainable business models as a subset of this wider trend, indicating how this lineage is starting to become interweaved with more general management scholarship.

\section{From Sustainable Production to Sustainable Consumption and Production}

Sustainable consumption emerged as a new policy agenda from the late 1990s (Cohen, 2001), through initiatives such as the United Nations Environment Programme's 'Marrakech Process'2 (initiated in 2002), in turn sparking a new line of research for several of the epistemic communities outlined above. First, proponents of ecological modernization theory turned towards a focus on consumption to complement earlier work on the ecological modernization of production (Spaargaren, 2003; Martens and Spaargaren, 2005). This coincided with a second strand emerging at the interface between STS and the sociology of consumption that developed new theoretical approaches drawing on the 'practice turn' in social science to study the dynamics of everyday practices - for example, eating and mobility (Shove, 2003; Warde, 2005). This included attention to how new technologies are absorbed and appropriated into everyday practice, and attempts to develop approaches to production and consumption systems via crossovers between the MLP and theories of everyday practice (McMeekin and Southerton, 2012; Hargreaves, Longhurst and Seyfang, 2013). A third and somewhat different strand reworked previous scholarship in innovation studies and STS to study the active roles of 'users' in sustainable innovation. Such studies have included the role of users in community-based and grassroots innovation (Hargreaves et al., 2013; Smith, Fressoli and Thomas, 2014).

More widely, academics have increasingly been debating sustainable consumption and production (SCP), resulting in various special issues in the Journal of Industrial Ecology (2005, 2010), Journal of Cleaner Production (2008), Natural Resources Forum (2010). This lineage combines the work of chemical and industrial engineers with that of social scientists in seeking solutions for the environmental impact of industrial processes and products. With increasing attention given to products, the focus shifted from industry and production processes, to one where consumption practices are included in the analysis. An important venue for the development of research in this lineage has been the successive Cleaner Production Roundtables that have been organized in different global regions, with the first European roundtable held in 1994 (Anonymous, 1994).

An important current manifestation of this lineage is work on the circular economy. This concept reworks already existing technological options of recycling and reuse with a more encompassing vision of an economy where resources remain in circulation within a given economic system (Ghisellini, Cialani and Ulgiati, 2016).

Despite occupying a prominent position in policy agendas, academic approaches to the study of SCP remained highly differentiated both in terms of theoretical approach and normative orientation. For example, in a critical review of SCP scholarship, Geels et al. (2015) differentiate between three positions: 'reformist' (development of eco-efficiency 
innovations and consumers buying eco-efficient products); 'revolutionary' (critique of the mainstream, advocating the abolishment of consumerism); and 'reconfiguration' (focus on transitions in socio-technical systems and daily life practices).

\section{INTRODUCING THE INDIVIDUAL CHAPTERS}

Looking at the chapters in the handbook individually, authors have aimed to deepen the insight into one or more of the lineages presented above. In that sense, together they serve as a map of the field. In addition, chapters have a more explicit objective. Collectively, our distinct approach is to try as much as possible to tease out the specific nature of innovation processes that are associated with the normative orientation of sustainability. There are several qualities that are relevant here:

- SI is about innovation processes that are, at some level, consciously guided, which makes them different from innovation that is driven by creativity alone.

- The values that constitute sustainability are contested, which complicates processes of emergence, persistence and dissolution.

- Guided innovation itself is normatively contested, as it can be seen to contradict dominant ideologies on which economic activity is based. While such ideologies may favour some economic activity over others, they typically also include normative orientations towards specific forms of coordinating such activities. As a result, guidance through markets may be favoured over guidance by governmental agencies, and different orientations exist towards the inclusion of users/consumers in processes of innovation.

- The values that constitute sustainability are not fixed, and change in the course of the innovation process.

An alternative perspective on the chapters is based on our take on academic knowledge production as outlined in previous sections. This implies that selecting potential authors for a handbook chapter is not straightforward. In part this is due to the realization that lineages emerge and cross-fertilize over time. Individual academics, while often related to one lineage more than to others, each have a unique position in this web of lineages. To further complicate things, selection is only partially in the hands of the editors - people approached can decide not to participate, and thus change the overall make-up of the collection.

The preceding reflections serve to illuminate the simple fact that, although we feel confident that the handbook as a whole represents the main thrust of the field of sustainable innovation, it covers some parts much better than others. To deal with that inevitable fact, we have chosen to provide a brief description of each set of chapters, with pointers to insights and approaches that we would have liked to include, but were not able to. The sets of chapters are depicted in Figure 1.1, which provides insight into the overall logic as we discovered it during our workshop. 


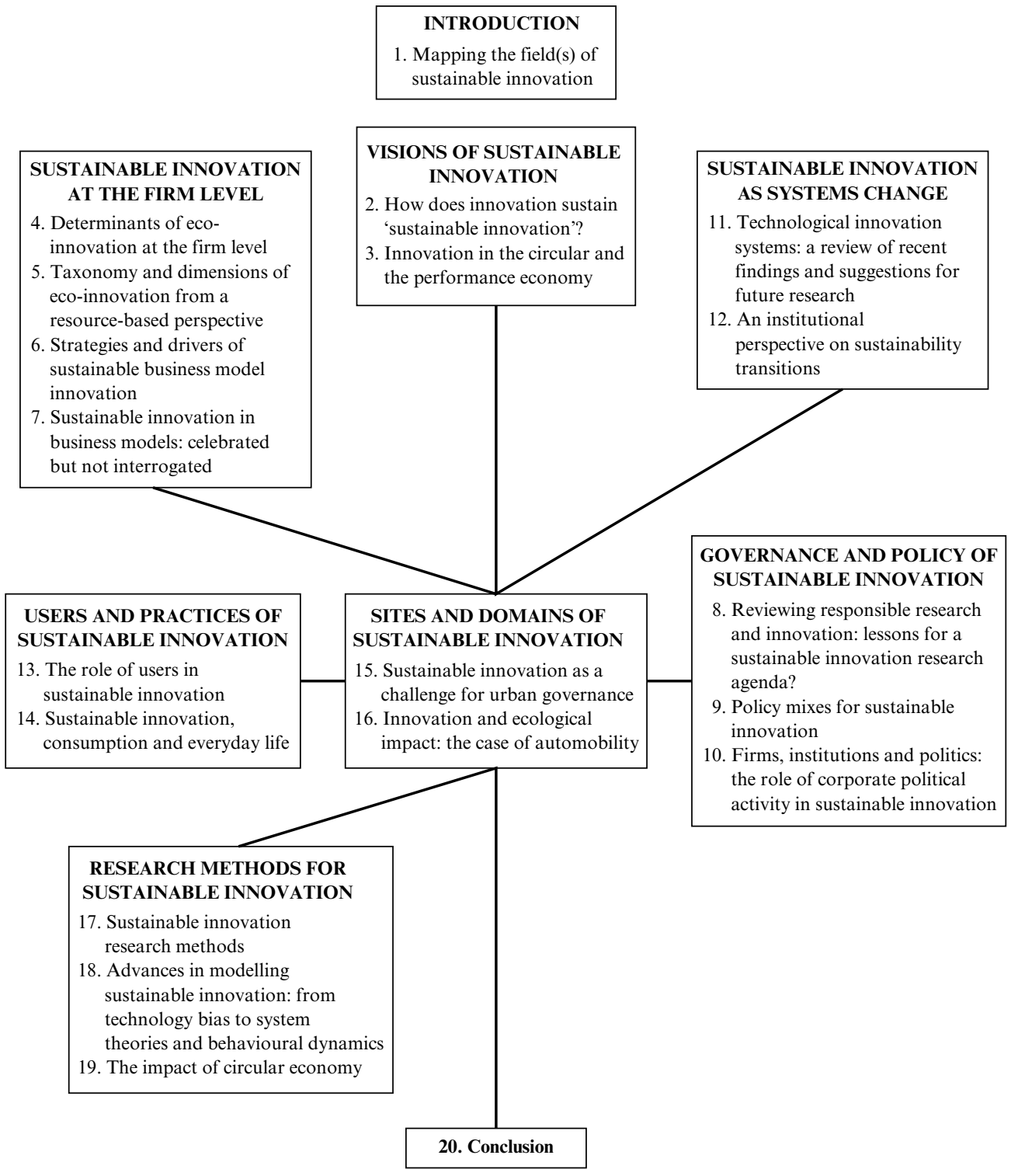

\section{Figure 1.1 Overview of handbook chapters}

\section{Part I: Visions of Sustainable Innovation}

One source for the multiplicity found in the field of sustainable innovation results from sustainability having a normative connotation, which has been variously interpreted. As an important reminder, Chapter 2 by Godin and Gaglio describes how the normative connotation of the concept of innovation itself has changed, from negative to positive. This sets the stage for reflecting on various visions of sustainable societies, which more 
or less explicitly translate into visions of what technological change, and associated social practices, is desirable. Stahel's chapter on the performance economy, Chapter 3, provides insight into the long trajectory that specific visions take to gain traction; in its first form articulated in the 1970s, it is currently influential as part of the notion of circular economy (a vision that underpins the work in Chapter 7 by Mont et al. and Chapter 19 by Ewen et al.). Given its explicit focus on changing the ways in which materials and products circulate through societies, these visions have a direct bearing on innovation.

The same can be said for visions we could not include, although arguably these focus more on changes in fundamental framings and valuations of economic activity. The sufficiency perspective (Princen, 2005) addresses the level of affluence in the IPAT formula we used in our introduction section. Although this may impact on the artefacts used, much of the realization of systems of production and consumption that provide in a sufficient, rather than abundant, way relates to changes in the ideational and competency dimension of social practices. The vision of degrowth (Schneider, Kallis and MartinezAlier, 2010; Kallis, 2011) tackles the even more fundamental notion of economic growth itself, acknowledging that to arrive at a sustainable level of steady state provision, a reversal of the growth process is required (see Van den Bergh, 2011 for insights on how this relates to technological change). In addition to these visions, ecological modernization theory should be mentioned here, as it combines an analytical perspective with a distinct normative orientation (Mol, 1995), where reflexive modernization leads to the further application of innovations in a way that contributes to decreased ecological impact.

\section{Part II: Sustainable Innovation at the Firm Level}

A strong tradition within the general field of innovation studies builds on the notion that the primary social site where innovation takes place is within private firms. From that the question that follows is, what antecedents lead firms to generate innovations? From this tradition, the lineage of environmental innovation flows, as can be seen in Chapter 4 by Horbach. Interestingly, while there are definite overlaps, the work on environmental and sustainable strategies, which we above described as dealing quite directly with process and product innovations, has developed without much cross-fertilization. Chapter 5 by Carrillo-Hermosilla et al. presents this work, adding ideas to provide it with new impetus.

The business model construct provides an indication that the firm, as a unit of analysis, is itself undergoing change. Indeed, sustainable business models to some extent result from a shift in the boundary between practices of production and consumption. This is partly due to wider technological change through information technology and smart devices. Thus, the construct enables a careful analysis of the interplay between change in material artefacts, physical infrastructure, and social practices. Chapter 6 by LüdekeFreund et al., provides insight into the evolution of the sustainable business model work, and its relation to innovation. Mont et al. in Chapter 7 then take a critical approach to sustainable innovation in business models, responding to the sometimes implicit reasoning regarding the actual ecological and social impact of business model innovation.

In this part of the handbook, we feel two topics would have deserved a chapter. The first is on grassroots innovation. For some time, there has been a distinct research line that seeks to challenge the notion that innovation is primarily driven by producers within the bounds of corporate organizations. Research on grassroots innovation maps such 
alternative sites of innovation (Seyfang and Smith, 2007). Closely related to this is the study of innovation in not-for-profit forms of provision, such as social enterprises and commoning initiatives. Each of these topics starts from the essential observation that much of the work on sustainable innovation takes for granted a specific type of economic system: the capitalist, growth-oriented, profit-driven firm producing for consumers. It relates back to normative visions of sustainability that do not take that system as a given.

\section{Part III: Governance and Policy of Sustainable Innovation}

A third theme around which we have organized chapters addresses two key questions related to technological change and sustainability. A first question is: what social mechanisms come into play when new technologies are contested? A second question is: how can the variety of tools available to public organizations (that is, regulation, public policy-making, taxation) be used to facilitate, speed up, and guide the change process?

The first question invites an inclusive perspective, both in terms of actors involved and in terms of the values underlying the contestation of a new technology. This question was one of the early areas of attention for research on technological change under the banner of technology assessment (TA). As any assessment somehow employs a set of values (whether externally imposed or endogenously generated), TA links back to visions of what constitutes a sustainable innovation. Key here is the realization that such visions are specific for actors within specific contexts. As a result, this work typically focuses on the processes through which contestation manifests itself, and the ways in which societal decision-making processes can be designed to adequately address conflicting values. The current label for this work is responsible innovation, and is presented in Chapter 8 by Cuppen et al.

The second question is also addressed in research on the antecedents of eco-innovation at the firm level, where public policy and regulation is theorized to be a main antecedent. It has been studied from the perspective of the intervening government, with the aim of understanding which type of policy programme and regulation serves best to induce specific types of innovation (Kemp, 1997). Over time, a shift (which parallels public administration more generally) has taken place from a focus on singular regulations and policy instruments to policy mixes. Chapter 9 by Rogge reflects this shift, in surveying the research on policy mixes in relation to sustainable innovation. As a direct counterpoint, Chapter 10 by Pinkse presents work on the way in which firms strategize to influence such governmental interventions.

In addition to these key topics, other work could have been included. Complementary to the three chapters, candidates would be research on important empirical phenomena such as global environmental governance (Biermann and Pattberg, 2008), and the variety of approaches through which efforts to reduce the social and environmental impact of international value chains is pursued (Seuring and Müller, 2008; Bolwig et al., 2010; Boons, Baumann and Hall, 2012).

\section{Part IV: Sustainable Innovation as Systems Change}

Systemic approaches to the study of innovation embrace multiple and interacting dimensions of change. Early contributions to the innovation studies literature emphasized how 
innovation systems comprise technologies, social networks (of innovating organizations) and institutions (both formal and informal). These earlier ideas were further elaborated into a functions approach to understanding the emergence and propagation of technological innovation systems (TISs). Chapter 11 by Bergek provides a comprehensive review of TIS studies; while the TIS approach is applicable to a wide range of innovations, Bergek describes how many studies have focused on sustainable innovations.

A second important contribution takes a different view of the systemic characteristics of innovation. In these studies, the focus is on the transformation of the socio-technical system. In other words, it is the socio-technical system that is the object of innovation. The multi-level perspective has developed as a prominent framework within this literature. While its application is also relevant to any major system transition, it was principally developed in the context of contemporary sustainable challenges in the belief that those challenges could only be met through societal changes of appropriate depth and scope. Chapter 12 by Fuenfschilling takes up one of the key debates within the system innovation literature concerned with explanations of processes and mechanisms of institutional change that constitute socio-technical system transitions, drawing on theories of organizational institutionalism.

This strategy of turning to wider debates in the social sciences has become increasingly common in the literature of the systemic characteristics of sustainable innovation. As such, the two chapters in this section are embedded within a wider debate of proliferating issues and foci. Combinations of insights from evolutionary economics, STS, institutional theory, political theory and geography have led to further elaborations and extensions, including the formation, protection and empowerment of radical niches (Smith and Raven, 2012), the role of politics and power in system transition (Meadowcroft, 2009), and the spatial dynamics of system transition pathways (Coenen and Truffer, 2012).

\section{Part V: Users and Practices of Sustainable Innovation}

Compared to scholarship that tackles the supply side of sustainable innovation, considerations of demand and consumption have remained marginal, reflecting a longer-term and persistent pattern in the broader field of STIS. While the literature on socio-technical systems makes strong claims about including 'user practices' within its frameworks for analysis, attention to consumption dynamics has largely been restricted to cases of 'special users' who become involved in co-developing radical niche innovations. However, attention to the roles that users perform in relation to sustainable innovation is now beginning to grow. Chapter 13 by Verbong et al. captures recent developments, offering an analysis of scholarship that looks at the various roles of users in general, and then specifically the roles that users perform in more transformative system innovation.

The term 'user' is somewhat idiosyncratic to the STIS literature, which stems from the focus on human action as it relates to the use of a specific technology. A parallel strand of scholarship starts from a different perspective, drawing on the sociology of consumption and recent applications and developments of theories of practice. Here analysis starts with the logic and dynamics of everyday practices, such as driving or eating, and this approach and its crossovers to ideas of domestication and appropriation from STS are discussed in Chapter 14 by Mylan.

Both of these chapters are principally based on sociological studies and consequently 
represent only a subset of potential relevant literature in the area. As such, we recognize that much of the wider scholarship within economics, psychology and management studies provides additional insight about how aggregate consumer demand influences the direction of technological change, the specific challenges of communicating and marketing new 'green' products and services, and the challenges of social acceptability faced by innovators introducing new innovations.

\section{Part VI: Sites and Domains of Sustainable Innovation}

The previous chapters all focus on an analytical dimension of sustainable innovation. The chapters in this section deviate from that: they combine different analytical dimensions in order to provide deeper insight into sustainable innovation in a specific empirical domain. Rohracher and Ornetzeder conceptualize sustainable innovation in the context of urban systems in Chapter 15, while in Chapter 16 Wells draws on a wide range of research to provide an analysis of sustainable innovation in the automotive production and consumption system. Both chapters provide an illustration of how trends in such empirical cases can only be understood through combining the analytical dimensions presented in Chapters 2 to 14.

\section{Part VII: Research Methods for Sustainable Innovation}

As this handbook seeks to provide an agenda for future research, it would not be complete without an explicit assessment of the methodological approaches that researchers have used to empirically analyse processes of sustainable innovation. Chapter 17 by Alkemade sets the stage by providing an overview of the methodologies that have been used in relation to particular theoretical approaches and analytical dimensions. Köhler in Chapter 18 then maps in more detail the uses of modelling in order to capture the dynamics of processes of innovation. Finally, in Chapter 19, Ewen et al. shed light on the important topic of how to assess the impact of sustainable innovation, through the example of circular economy innovations.

\section{NOTES}

1. This seems at least partially to come out of a changing policy orientation in Germany (Duales System) and the Netherlands (life-cycle analysis development, integrated chain management). The rationalization was: if we use the firm as system boundary there are all kinds of under- or misrepresented impacts (the PhD thesis by Gjalt Huppes, 1993, is perhaps a good source).

2. The United Nations Environment Programme's 10-Year Framework of Programmes on Sustainable Consumption and Production.

\section{REFERENCES}

Abbott, A. (2016), Processual Sociology, Chicago, IL: University of Chicago Press.

Angelo, F.D., C.J.C. Jabbour and S.V. Galina (2012), 'Environmental innovation: in search of a meaning', World Journal of Entrepreneurship, Management and Sustainable Development, 8(2/3), 113-21.

Anonymous (1994), European Roundtable on Cleaner Production Programs, 2(3), 8010. 
Ashford, N., C. Ayers and R. Stone (1985), 'Using regulation to change the market for innovation', Harvard Environmental Law Review, 9(2), 419-66.

Ayres, R.U. and L. Ayres (1996), Industrial Ecology - Towards Closing the Materials Cycle, Cheltenham, UK and Brookfield, VT, USA: Edward Elgar Publishing.

Ayres, R.U. and L. Ayres (eds) (2002), A Handbook of Industrial Ecology, Cheltenham, UK and Northampton, MA, USA: Edward Elgar Publishing.

Ayres, R.U. and A.V. Kneese (1969), 'Production, consumption, and externalities', The American Economic Review, 59(3), 282-97.

Ayres, R.U. and A.V. Kneese (1971), 'Economic and ecological effects of a stationary economy', Annual Review of Ecology and Systematics, 2(1), 1-22.

Bansal, P. and A.J. Hoffman (eds) (2012), The Oxford Handbook of Business and the Natural Environment, Oxford: Oxford University Press.

Bergek, A., S. Jacobsson and B. Carlsson et al. (2008), 'Analyzing the functional dynamics of technological innovation systems: a scheme of analysis', Research Policy, 37, 407-29.

Berkhout, F. (2011), 'Eco-innovation: reflections on an evolving research agenda', International Journal of Technology, Policy and Management, 11(3/4), 191-7.

Berkhout, F. (2014), 'Sustainable innovation management', in M. Dodgson, D. Gann and N. Phillips (eds), The Oxford Handbook of Innovation Management, Oxford: Oxford University Press, pp. 290-315.

Biermann, F. and P. Pattberg (2008), 'Global environmental governance: taking stock, moving forward', Annual Review of Environment and Resources, 33, 277-94.

Bijker, W.E., T.P. Hughes and T.J. Pinch (eds) (1987), The Social Construction of Technological Systems, Cambridge, MA: MIT Press.

Bolwig, S., S. Ponte and A. Du Toit et al. (2010), 'Integrating poverty and environmental concerns into valuechain analysis: a conceptual framework', Development Policy Review, 28(2), 173-94.

Boons, F. (2013), 'Organizing within dynamic ecosystems: conceptualizing socio-ecological mechanisms', Organization \& Environment, 26(3), 281-97.

Boons, F. and F. Lüdeke-Freund (2013), 'Business models for sustainable innovation: state-of-the-art and steps towards a research agenda', Journal of Cleaner Production, 45, 9-19.

Boons, F., L. Baas and J.J. Bouma et al. (2000), 'Trajectories of greening: the diffusion of green organizational routines in the Netherlands, 1986-1995', International Studies of Management \& Organization, 30(3), $18-40$.

Boons, F., H. Baumann and J. Hall (2012), 'Conceptualizing sustainable development and global supply chains', Ecological Economics, 83, 134-43.

Boulding, K.E. (1966), 'The economics of the coming Spaceship Earth', in H.E. Daly (ed.), Environmental Quality Issues in a Growing Economy, Baltimore, MD: Johns Hopkins University Press.

Bulkeley, H. (2001), 'No regret? Economy and environment in Australia's domestic climate change policy process', Global Environmental Change, 11(2), 155-69.

Carlsson, B. and R. Stankiewicz (1991), 'On the nature, function and composition of technological systems', Evolutionary Economics, 1, 93-118.

Chertow, M.R. (2000), 'The IPAT equation and its variants', Journal of Industrial Ecology, 4(4), 13-29.

Clift, R. (1995), 'Clean technology - an introduction', Journal of Chemical Technology and Biotechnology, 62, 321-6.

Coenen, L. and B. Truffer (2012), 'Places and spaces of sustainability transitions: geographical contributions to an emerging research and policy field', European Planning Studies, 20(3), 367-74.

Cohen, M. (2001), 'The emergent environmental policy discourse on sustainable consumption', in M. Cohen and J. Murphy (eds), Exploring Sustainable Consumption: Environmental Policy and the Social Sciences, London: Pergamon, pp. 21-37.

Cole, H.S.D., C. Freeman, M. Jahoda and K.L.R. Pavitt (1973), Models of Doom. Critique of Limits to Growth, New York: Universe Books.

Costanza, R. (1989), 'What is ecological economics?', Ecological Economics, 1, 1-7.

Dunlap, R.E. (2002), 'Environmental sociology: a personal perspective on its first quarter century', Organization and Environment, 15, 10-29.

Fagerberg, J., M. Fosaas and K. Sapprasert (2012), 'Innovation: exploring the knowledge base', Research Policy, 41, 1132-53.

Fischer, K. and J. Schot (eds) (1993), Environmental Strategies for Industry: International Perspectives on Research Needs and Policy Implications, Washington, DC: Island Press.

Foray, D. and A. Grübler (1996), 'Technology and the environment: an overview', Technological Forecasting and Social Change, 53, 3-13.

Freeman, C. (1984), 'Prometheus unbound', Futures, 16(5), 494-507.

Freeman, C. (1992), The Economics of Hope: Essays on Technical Change, Economic Growth, and the Environment, London: Pinter Publishers. 
Freeman, C. (1996), 'The greening of technology and models of innovation', Technological Forecasting and Social Change, 53(1), 27-39.

Friedman, M. (1970), 'The social responsibility of business is to increase its profits', New York Times Magazine, 13 September 1970.

Geels, F.W. (2002), 'Technological transitions as evolutionary reconfiguration processes: a multi-level perspective and a case-study', Research Policy, 31, 1257-74.

Geels, F.W. (2004), 'From sectoral systems of innovation to socio-technical systems: insights about dynamics and change from sociology and institutional theory', Research Policy, 33, 897-920.

Geels, F.W., A. McMeekin, J. Mylan and D. Southerton (2015), 'A critical appraisal of sustainable consumption and production research: the reformist, revolutionary and reconfiguration agendas', Global Environmental Change, 34, 1-12.

Georgescu-Roegen, N. (1971), The Entropy Law and the Economic Process, Cambridge, MA: Harvard University Press.

Ghisellini, P., C. Cialani and S. Ulgiati (2016), 'A review on circular economy: the expected transition to a balanced interplay of environmental and economic systems', Journal of Cleaner Production, 114, 11-32.

Gouldson, A. and J. Murphy (1997), 'Ecological modernisation: restructuring industrial economies', The Political Quarterly, 68(8), 74-86.

Green, K., A. McMeekin and A. Irwin (1994), 'Technological trajectories and R\&D for environmental innovation in UK firms', Futures, 26(10), 1047-59.

Hajer, M. (1995), The Politics of Environmental Discourse: Ecological Modernization and the Policy Process, Oxford: Oxford University Press.

Hargreaves, T., N. Longhurst and G. Seyfang (2013), 'Up, down, round and round: connecting regimes and practices in innovation for sustainability', Environment and Planning A, 45, 402-20.

Hart, S. (1995), 'A natural-resource-based view of the firm', Academy of Management Review, 20, 986-1014.

Hart, S.L. and G. Dowell (2011), 'A natural resource-based view of the firm: fifteen years after', Journal of Management, 37, 1464-79.

Hekkert, M., R.A.A. Suurs and S. Negro et al. (2007), 'Functions of innovation systems: a new approach for analysing technological change', Technological Forecasting and Social Change, 74, 413-32.

Hoffman, A.J. and M.J. Ventresca (2002), Organizations, Policy and the Natural Environment: Institutional and Strategic Perspectives, Stanford, CA: Stanford University Press.

Hojnik, J. and M. Ruzzier (2016), 'What drives eco-innovation? A review of an emerging literature', Environmental Innovation and Societal Transitions, 19, 31-41.

Huber, J. (1985), Die Regenbogen-Gesellschaft: Ökologie und Sozialpolitik [The Rainbow Society: Ecology and Social Policy], Frankfurt: S. Fischer.

Hull, D.L. (1988a), 'A mechanism and its metaphysics: an evolutionary account of the social and conceptual development of science', Biology and Philosophy, 3(2), 123-55.

Hull, D.L. (1988b), Science as a Process: An Evolutionary Account of the Social and Conceptual Development of Science, Chicago, IL: University of Chicago Press.

Huppes, G. (1993), 'Macro-environmental policy: principles and design: with cases on milk packaging, cadmium, phosphorus and nitrogen, and energy and global warming', PhD thesis, Leiden University.

Ilinitch, A.Y. and S.C. Schaltegger (1995), 'Developing a green business portfolio', Long Range Planning, 28(2), 29-38.

Irwin, A. (1995), Citizen Science: A Study of People, Expertise and Sustainable Development, London: Routledge.

Irwin, A. and P.D. Hooper (1992), 'Clean technology, successful innovation and the "greening of industry", Business Strategy and the Environment, 1(2), 1-12.

Jacobsson, S. and A. Bergek (2004), 'Transforming the energy sector: the evolution of technological systems in renewable energy technology', Industrial and Corporate Change, 13, 815-49.

Jaffe, A., R. Newell and R. Stavins (2003), 'Technological change and the environment', in K.G. Male and J. Vincent (eds), Handbook of Environmental Economics, Amsterdam: North-Holland, pp. 461-516.

Kallis, G. (2011), 'In defence of degrowth', Ecological Economics, 70(5), 873-80.

Kemp, R. (1994), 'Technology and environmental sustainability: the problem of technological regime shifts', Futures, 26(10), 1023-46.

Kemp, R. (1997), Environmental Policy and Technical Change, Cheltenham, UK and Lyme, NH, USA: Edward Elgar Publishing.

Kemp, R. and V. Oltra (2011), 'Research insights and challenges on eco-innovation dynamics', Industry and Innovation, 18, 249-53.

Kemp, R. and S. Pontoglio (2011), 'The innovation effects of environmental policy instruments - a typical case of the blind men and the elephant?', Ecological Economics, 72, 28-36.

Kemp, R. and L. Soete (1992), 'The greening of technological progress', Futures, 24(5), 437-57.

Luten, D. (1980), 'Ecological optimism in the social sciences', American Behavioral Scientist, 24(1), $125-51$. 
Martens, S.G. and G. Spaargaren (2005), 'The politics of sustainable consumption: the case of the Netherlands', Sustainability: Science, Practice and Policy, 1(1), 1-14.

Massa, L., C. Tucci and A. Afuah (2016), 'A critical assessment of business model research', Academy of Management Annals, 11(1), 73-104.

McMeekin, A. and D. Southerton (2012), 'Sustainability transitions and final consumption: practices and socio-technical systems', Technology Analysis \& Strategic Management, 24(4), 345-61.

Meadowcroft, J. (2009), 'What about the politics? Sustainable development, transition management, and long term energy transitions', Policy Science, 42(4), 323-40.

Meadows, D.H., D.L. Meadows, J. Randers and W.W. Behrens (1972), The Limits to Growth, New York: Signet.

Mol, A.P. (1995), 'The refinement of production', PhD thesis, Wageningen University.

Porter, M.E. and C. van der Linde (1995), 'Toward a new conception of the environment-competitiveness relationship', The Journal of Economic Perspectives, 9(4), 97-118.

Princen, T. (2005), The Logic of Sufficiency, Volume 30, Cambridge, MA: MIT Press.

Rennings, K. (2000), 'Redefining innovation - eco-innovation research and the contribution from ecological economics', Ecological Economics, 32(2), 319-32.

Rip, A. (1986), 'Controversies as informal technology assessment', Knowledge: Creation, Diffusion, Utilization, 8(2), 349-71.

Rip, A. (1992), 'A quasi-evolutionary model of technological development and a cognitive approach to technology policy', Rivista di Studi Epistemologici e Sociali Sulla Scienza e la Technologia, 2, 69-103.

Rip, A. (1995), 'Introduction of new technology: making use of recent insights from sociology and economics of technology', Technology Analysis \& Strategic Management, 7, 417-31.

Rip, A. and R. Kemp (1998), 'Technological change', in S. Rayner and E.L. Malone (eds), Human Choices and Climate Change, Volume 2, Resources and Technology, Columbus, OH: Battelle.

Rip, A. and H. van den Belt (1988), Constructive Technology Assessment: Toward a Theory, Zoetermeer: Office of Science Policy, Ministry of Education and Sciences.

Rip, A., J. Schot and T.J. Misa (eds) (1995), Managing Technology in Society: The Approach of Constructive Technology Assessment, London: Pinter.

Roome, N. (1994), 'Business strategy, R\&D management and environmental imperatives', R\&D Management, 24(1), 65-82.

Røpke, I. (2004), 'The early history of modern ecological economics', Ecological Economics, 50(3-4), $293-314$.

Røpke, I. (2005), 'Trends in the development of ecological economics from the late 1980s to the early 2000s', Ecological Economics, 55(2), 262-90.

Schnaiberg, A. (1980), The Environment: From Surplus to Scarcity, New York: Oxford University Press.

Schnaiberg, A. and K.A. Gould (1994), Environment and Society, New York: St. Martin's Press.

Schneider, F., G. Kallis and J. Martinez-Alier (2010), 'Crisis or opportunity? Economic degrowth for social equity and ecological sustainability. Introduction to this special issue', Journal of Cleaner Production, 18(6), 511-18.

Schot, J.W. (1992), 'Constructive technology assessment and technology dynamics: opportunities for the control of technology - the case of clean technologies', Science, Technology and Human Values, 17(1), 36-57.

Schot, J. and F.W. Geels (2008), 'Strategic niche management and sustainable innovation journeys: theory, findings, research agenda, and policy', Technology Analysis \& Strategic Management, 20, 537-54.

Seuring, S. and M. Müller (2008), 'From a literature review to a conceptual framework for sustainable supply chain management', Journal of Cleaner Production, 16(15), 1699-710.

Seyfang, G. and A. Smith (2007), 'Grassroots innovations for sustainable development: towards a new research and policy agenda', Environmental Politics, 16(4), 584-603.

Shove, E. (2003), Comfort, Cleanliness and Convenience: The Social Organization of Normality, Oxford: Berg.

Smith, A. and R. Raven (2012), 'What is protective space? Reconsidering niches in transitions to sustainability', Research Policy, 41, 1025-36.

Smith, A., M. Fressoli and H. Thomas (2014), 'Grassroots innovation movements: challenges and contributions', Journal of Cleaner Production, 63, 114-24.

Smith, A., J.-P. Voss and J. Grin (2010), 'Innovation studies and sustainability transitions: the allure of the multi-level perspective and its challenges', Research Policy, 39, 435-48.

Socolow, R.H., C. Andrews, F. Berkhout and V. Thomas (1994), Industrial Ecology and Global Change, Cambridge, UK: Cambridge University Press.

Soete, L. and A. Arundel (eds) (1993), An Integrated Approach to European Innovation and Technology Diffusion Policy: A MAASTRICHT MEMORANDUM, Brussels-Luxembourg: European Commission.

Spaargaren, G. (2000), 'Ecological modernization theory and domestic consumption', Journal of Environmental Policy and Planning, 2(4), 323-35.

Spaargaren, G. (2003), 'Sustainable consumption: a theoretical and environmental policy perspective', Society and Natural Resources, 16(8), 687-701.

Spaargaren, G. and A.P.J. Mol (1992), 'Sociology, environment and modernity: ecological modernisation as a theory of social change', Society and Natural Resources, 5(4), 323-44. 
Stahel, W. (1982), 'The product life factor', in G.S. Orr (ed.), An Inquiry into the Nature of Sustainable Societies: The Role of the Private Sector, Houston, TX: Houston Area Research Centre, pp. 72-105.

Stilgoe, J., R. Owen and P. Macnaghtnen (2013), 'Developing a framework for responsible innovation', Research Policy, 42, 1568-80.

Stirling, A. (2008), "Opening up" and "closing down" power: participation and pluralism in the social appraisal of technology', Science, Technology and Human Values, 33(2), 262-94.

Stubbs, W. and C. Cocklin (2008), 'Conceptualizing a "sustainability business model", Organization \& Environment, 21(2), 103-27.

Toulmin, S. (1974), Human Understanding, Volume I: The Collective Use and Evolution of Concepts, Princeton, NJ: Princeton University Press.

Tukker, A. (2015), 'Product services for a resource-efficient and circular economy - a review', Journal of Cleaner Production, 97, 76-91.

Van den Belt, H. and A. Rip (1987), 'The Nelson-Winter-Dosi model and synthetic dye industry', in W.E. Bijker, T.P. Hughes and T.J. Pinch (eds), The Social Construction of Technological Systems, Cambridge, MA: MIT Press, pp. 135-58.

Van den Bergh, J.C. (2011), "Environment versus growth - a criticism of "degrowth" and a plea for "a-growth", Ecological Economics, 70(5), 881-90.

Vickers, I. and M. Cordey-Hayes (1999), 'Cleaner production and organizational learning', Technology Analysis \& Strategic Management, 11(1), 75-94.

Warde, A. (2005), 'Consumption and theories of practice', Journal of Consumer Culture, 5(2), 131-54.

Winn, S.F. and N. Roome (1993), 'R\&D management responses to the environment. Current theory and implications for practice and research', $R \& D$ Management, 23, 147-60.

Yearley, S. (2008), 'Nature and the environment in science and technology studies', in E. Hackett, O. Amsterdamska, M. Lynch and J. Wajcman (eds), The Handbook of Science and Technology Studies, 3rd edition, Cambridge, MA: MIT Press.

York, R. and R.A. Rosa (2003), 'Key challenges to ecological modernization theory: institutional efficacy, case study evidence, units of analysis, and the pace of eco-efficiency', Organization \& Environment, 16(3), $273-88$.

York, R., E.A. Rosa and T. Dietz (2003), 'STIRPAT, IPAT and ImPACT: analytic tools for unpacking the driving forces of environmental impacts', Ecological Economics, 46(3), 351-65. 